УДК 338.23:336.131(494)

https://doi.org/10.24866/1813-3274/2020-4/91-104

С. Е. Демидова ${ }^{1}$, Финансовый университет при Правительстве

Российской Федерации, г. Москва, Россия

E-mail: sedemidova@fa.ru

Н. Л. Воронина ${ }^{2}$, Финансовый университет при Правительстве

Российской Федерации, г. Москва, Россия

E-mail: n.voronina.00@bk.ru

\title{
ПОЛИТИКА УСТОЙЧИВОГО РАЗВИТИЯ КАК ОСНОВА УПРАВЛЕНИЯ ОБЩЕСТВЕННЫМИ ФИНАНСАМИ (НА ПРИМЕРЕ ШВЕЙЦАРИИ)
}

Аннотация. Статья посвящена рассмотрению особенностей управления общественными финансами в парадигме устойчивого развития и влияния на социальные, экономические и экологические процессы в государстве. Концепция устойчивого развития была впервые рассмотрена в 1987 г., но в большинстве стран мира формирование социально-экономической политики на принципах устойчивости связано с принятием глобального документа «Цели в области устойчивого развития» (англ. Sustainable Development Goals). Швейцария является одной из стран, которая на законодательном уровне закрепила достижение устойчивого развития как национальную цель, реализуемую в рамках деятельности всех субъектов хозяйствования, в том числе в сфере управления общественными финансами. Посредством принятия Стратегии устойчивого развития осуществляется интеграция международных приоритетов развития в систему стратегического управления Швейцарии, которая затрагивает все уровни бюджетной системы. При формировании и изменении данного документа применяются трёхмерная модель устойчивого развития и модель основного капитала, суть которых раскрыта в статье. В ходе исследования было выявлено, что за период 2000-2020 гг. Швейцарии удалось повысить уровень устойчивости общественных финансов, а также социальную ориентированность: существенно снизились доля уровня государственного долга и объема дефицита федерального бюджета по отношению к ВВП, наблюдался рост доли расходов на

\footnotetext{
${ }^{1}$ Светлана Евгеньевна Демидова, кандидат экономических наук, доцент, доцент департамента общественных финансов Финансового университета при Правительстве Российской Федерации, г. Москва, Россия.

${ }^{2}$ Наталья Леонидовна Воронина, магистрант финансового факультета Финансового университета при Правительстве Российской Федерации, г. Москва, Россия.

Для ичитирования: Демидова С. Е., Воронина Н. Л. Политика устойчивого развития как основа управления общественными финансами (на примере Швейцарии) // Азиатско-Тихоокеанский регион: экономика, политика, право. 2020. № 4. С. 91-104. DOI https://doi.org/10.24866/1813-3274/2020-4/91-104.
}

(C) Демидова С. Е., Воронина Н. Л., 2020 
социальное обеспечение, науку и образование. Применяемые меры контрциклической политики позволяют балансировать сальдо бюджетов бюджетной системы Швейцарии посредством установления бюджетных ограничений на размер расходной части, на которые оказывают влияние совокупность внешних и внутренних факторов. Текущий кризис, вызванный новой волной коронавирусной инфекции, отразился на финансовом результате федерального бюджета по итогам 2020 г. и изменил плановые показатели до 2024 г. В заключительной части проведен сравнительный анализ систем стратегического управления Швейцарии и России, выявлены проблемы отечественной системы. Обоснована возможность применения в российской практике швейцарских моделей с учётом особенностей нашей страны.

Ключевые слова: устойчивое развитие, общественные финансы, стратегия развития, цели устойчивого развития, национальные цели, стратегические документы, показатели федерального бюджета, Швейцария, трёхмерная модель, модель основного капитала, социальная политика, государственный долг, инвестиционная активность, расходные обязательства, дефицит бюджета, контрциклическая политика, структурный дефицит, циклический дефицит, государственный внебюджетный фонд, государственные программы.
N. L. Voronina ${ }^{1}$, Financial University under the Government
of the Russian Federation, Moscow, Russia
E-mail: n.voronina.00@bk.ru
S. E. Demidova ${ }^{2}$, Financial University under the Government
of the Russian Federation, Moscow, Russia
E-mail: sedemidova@fa.ru

\section{SUSTAINABLE DEVELOPMENT POLICY AS A CORNERSTONE OF PUBLIC FINANCIAL MANAGEMENT IN SWITZERLAND}

Abstract. The article discusses features of public finance management in the paradigm of sustainable development and impact on social, economic and environmental processes in the state. The Sustainable development concept was first considered in 1987, but the formation of social and economic policies based on the principles of sustainability is associated with the adoption of the global document "Sustainable Development Goals" in most

\footnotetext{
${ }^{1}$ Natalia Leonidovna Voronina, Master Student, Financial University under the Government of the Russian Federation, Moscow, Russia.

${ }^{2}$ Svetlana Evgenievna Demidova, PhD (Economics), Associate Professor, Department of Public Finance, Financial University under the Government of the Russian Federation, Moscow, Russia.

For citing: Voronina N. L., Demidova S. E. Sustainable development policy as a cornerstone of public financial management in Switzerland // PACIFIC RIM: Economics, Politics, Law. 2020. No. 4. P. 91-104. DOI https://doi.org/10.24866/1813-3274/2020-4/91-104.
} 
countries of the world. Switzerland is one of the countries that has enshrined the achievement of sustainable development as a national goal at the legislative level. This goal is implemented in all incorporated and unincorporated businesses activities, including in the field of public finance management. Through the adoption of the Sustainable Development Strategy, international development priorities are being integrated into Switzerland's strategic management system, which affects all the budgetary system levels. During forming and changing this document, a three-dimensional model of sustainable development and a model of fixed capital are used, the essence of which is disclosed in the article. The article analyses that Switzerland had to increase the level of public finances stability, as well as social orientation in 2000-2020: the share of the level of public debt and the volume of the federal budget deficit in relation to GDP has decreased significantly, and the share of spending on social security, science and education has grown. The applied countercyclical policy measures allow balancing the budget balance of the Swiss budgetary system by setting budgetary restrictions on the expenditure, which is influenced by a combination of external and internal factors. The current crisis caused by the new coronavirus infection is affecting the federal budget financial results of the current year and changing the planned targets until 2024. As a result of the study, the authors make comparative analysis of the Swiss and Russian strategic management systems, and identify problems of the domestic system. The possibility of implementing Swiss models in Russian practice are demonstrated taking into account the special aspects of our country.

Keywords: sustainable development, public finance, development strategy, sustainable development goals, national goals, strategic documents, budget target, Switzerland, three-dimensional model, fixed capital model, social policy, public debt, investment activity, expenditure commitments, budget deficit, anti-cyclical policy, structural deficit, cyclical deficit, state non-budgetary fund, government programs.

Впервые вопрос качественного развития на глобальном уровне был сформулирован в отчёте Всемирной комиссии по окружающей среде и развитию ООН в 1987 г. «Наше общее будущее» [1]. В нём раскрывается один из подходов к понятию устойчивого развития - развитие, которое удовлетворяет потребности текущего поколения, без ущерба для удовлетворения потребностей будущих поколений. Изложенная в документе концепция подразумевает необходимость первостепенного внимания к мировой проблеме бедности населения, а также учёту рестрикций, связанных с ограниченностью ресурсов и возможностями восстановления окружающей среды (в привязке к технологическому развитию и социальной организации). В 2015 г. всеми государствами-членами ООН принимается Повестка дня в области устойчивого развития на период до 2030 г.: 17 целей как инструмент достижения мира и процветания, искоренения нищеты и защиты планеты. Достижение страте- 
гических целей требует активного участия как отдельных институциональных субъектов, органов власти конкретного государства, корпораций, населения, так и в целом мирового сообщества. В сфере устойчивого финансирования значительный акцент делается на то, что традиционная финансовая парадигма постепенно вытесняется устойчивой

Исходя из рейтинга стран мира по индексу процветания, рассчитываемого Институтом Legatum, который учитывает девять аспектов и параметров общества (экономика, предпринимательство, управление, образование и иные), Швейцария на протяжении 10 лет стабильно занимает 3-ю позицию. Наиболее существенным образом за этот период улучшилось обеспечение безопасности и правовой защищённости [2].

Ориентир на устойчивое развитие находит свое отражение в стратегических документах управления общественными финансами Швейцарии с 1997 г., когда была разработана и принята первая стратегия «Устойчивое развитие в Швейцарии». Впоследствии, по мере достижения целей, принимались новые Стратегии устойчивого развития (2002, 2008, 2012, 2016 гг.). В Федеральной Конституции Швейцарской Конфедерации [3], в ст. 2, устойчивое развитие, наряду с всеобщим благосостоянием, национальной сплочённостью и культурным многообразием, признаётся национальной целью Швейцарии. Кроме того, в ст. 73 закреплено, что конфедерация и кантоны должны стремиться к достижению баланса и устойчивости в отношениях между природой, её способностью к восстановлению, и потребностями со стороны населения.

В основе формирования и проведения политики устойчивого развития положены трёхмерная модель и модель основного капитала. Трёхмерная модель (рис. 1) отражает взаимообусловленность трёх сфер жизнедеятельности (окружающая среда, экономика и общество), которые рассматриваются во временном горизонте и в вертикальном «север - юг». Деятельность субъектов как государственного, так и частного сектора должна учитывать последствия совершаемых действий и принимаемых решений и их влияние на изменение всех сфер, не допуская одномерности и изолированности, учитывать то, как они отразятся на последующих поколениях.

Измерение «север - юг» отражает глобализационные и интеграционные процессы. Климатические и масштабные экологические проблемы невозможно решить на национальном уровне, экономические шоки одной страны зачастую отражаются на экономике других государств (кризис доткомов в США, санкции). Аналогичное влияние оказывает и нестабильность в социальной сфере (например, через увеличение миграционных потоков).

Трёхмерную модель дополняет модель основного капитала, предложенная Всемирным банком в 1994 г. Основная идея заключается в определении структуры капитала устойчивого развития как суммы трёх типов капитала: экологический, 
экономический и социальный. В зависимости от выбранной концепции «сильной» или «слабой» устойчивости устанавливаются допустимые варианты замещения одного капитала другим.

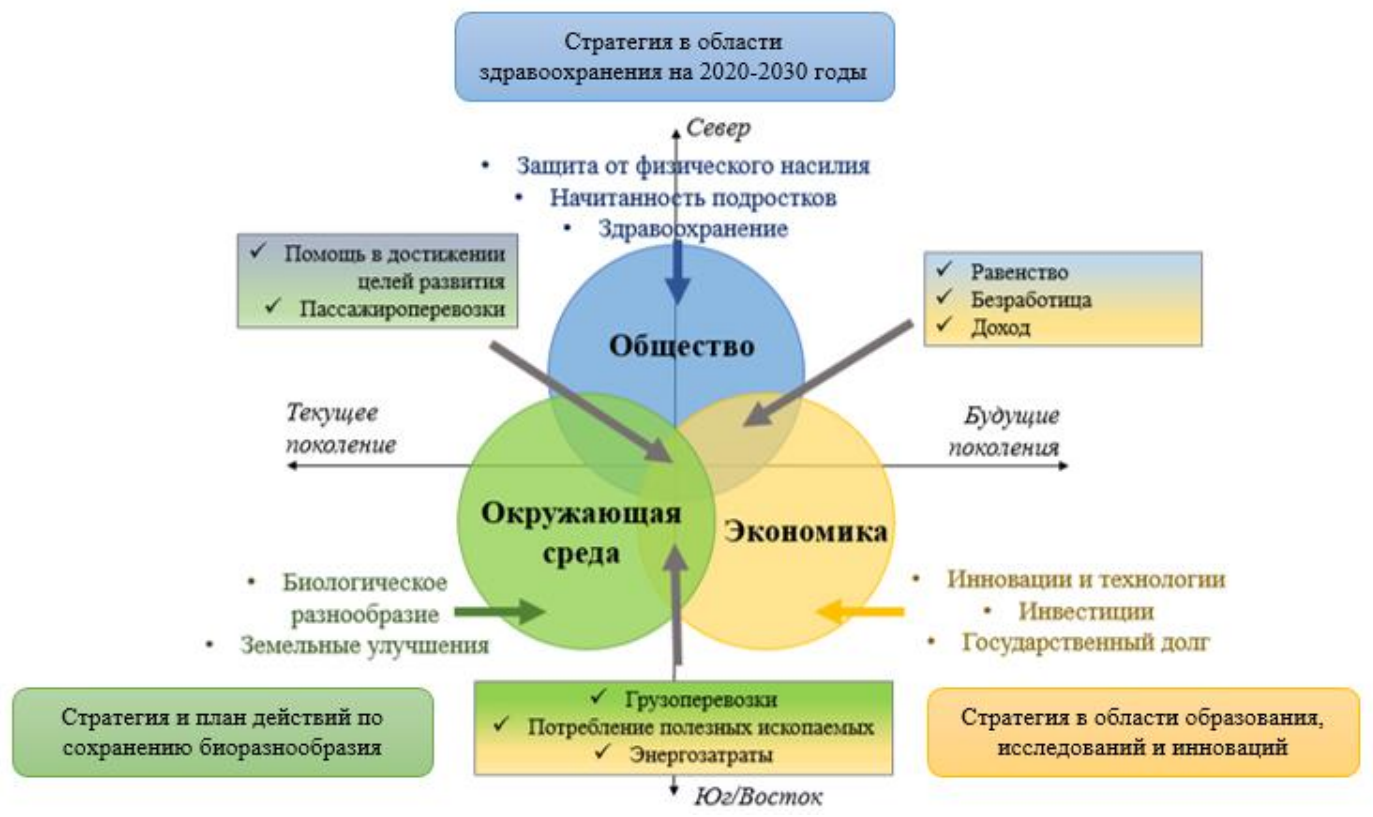

Puc. 1. Трёхмерная модель устойчивого развития с выделением ключевых направлений Источник: составлено авторами на основе [4]

Федеральный совет Швейцарии придерживается «разумной устойчивости», нивелируя крайние точки: компенсация одного капитала другим допустима в определённых рамках, не допуская истощения до критического уровня. Минимальные значения могут определяться различными стандартами (например, экологическими - уровень загрязнения воздуха), а также учитываются гарантированные законодательством права человека, которые определяют не подлежащие обсуждению минимальные требования или пороговые значения.

Государственная политика Швейцарии реализуется в рамках четырехлетних политических циклов и включает четыре последовательных этапа (рис. 2). На первом этапе составляется Стратегия устойчивого развития, которая выступает основным инструментом реализации целей устойчивого развития. Цель Стратегии обеспечение последовательного устойчивого развития страны посредством координации действий на уровне конфедерации, кантонов, общин, бизнеса и гражданского общества. За счёт формирования и реализации Стратегии Федеральный совет выполняет установленные конституцией обязанности по обеспечению устойчивого развития. 


\section{Составление \\ Стратегии \\ устойчивого развития \\ - Стратегия}

В середине каждого законодательного

периода

- Отчетность
Соответствующими федеральными органами

\section{- Реализация}

\section{С помощью системы мониторинга \\ "MONET"}

\section{- Мониторинг}

Puc. 2. Этапы реализации Целей в области устойчивого развития Источник: составлено авторами на основе [4]

Данный документ обновляется каждые четыре года вместе с проведением выборов законодательных и исполнительных органов власти, последние из которых произошли осенью 2019 г. Таким образом, в настоящее время Стратегия корректируется на период 2020-2030 гг. В данном документе устанавливаются 15 критериев устойчивости для оценки влияния принимаемых решений на три сферы (окружающая среда, экономика, общество) и соответствующие типы капитала.

Вторым этапом является непосредственная реализация Стратегии и связанные с ней иные отраслевые инструменты - этим занимаются соответствующие федеральные органы, в том числе посредством координации с органами власти кантонов. Ответственным исполнителем является Федеральный совет, который несёт высшую политическую ответственность за реализацию политики устойчивого развития Швейцарии.

Неотъемлемым элементом выступает мониторинг выполнения Стратегии и непосредственно целей устойчивого развития, который осуществляется с помощью специальной системы MONET [5]. На основе содержащейся в ней информации составляется отчётность: базовое исследование и отчёты по странам. В середине каждого законодательного периода формируются отчёты для ООН. Оценка эффективности принятых мер запланирована на 2022, 2026, 2030 гг., полученные результаты будут использованы для корректировки Стратегии на новый четырёхлетний период с учётом выявленных проблем и смещения приоритетов.

Например, цель устойчивого развития по искоренению бедности во всех её формах и проявлениях отражается в Стратегии устойчивого развития Швейца- 
рии как обеспечение покрытия социальных рисков посредством системы социального страхования и финансовой консолидации с учётом текущих возможностей национальной экономики. Показателем, отражающим достижение национальной цели, является доля общих расходов государственных и частных учреждений в области социального обеспечения в объёме ВВП, которая должна расти с каждым годом. За 30 лет значение индикатора выросло больше чем на 10\%: в 1990 г. - 17,5\%, в 2017 г. - превышало 28\% [6]. Стоит отметить, что реализация социальной политики осуществляется не только за счет системы государственных институтов, за исследуемый период возросла роль именно частных учреждений, оказывающих услуги в социальной сфере. Если в 1990 г. на долю частного сектора приходилось $5,4 \%$, то в 2018 г. - 11,5\%. Это обусловлено в том числе развитием смешанной системы страхования всех видов: при наличии государственного, функционирует и пользуется всё большим спросом с каждым годом система частного страхования.

Уровень государственного долга - один из индикаторов, характеризующих цель устойчивого развития: долговые обязательства допустимы в случае, если их наличие не ставит под угрозу выполнение всех возложенных функций на органы государственной власти и местного самоуправления, т.е. не должен превышать установленный порог (ограничения действуют с 2003 г. на уровне федерации и в ряде кантонов). Совокупный государственный долг Швейцарии (рис. 3) по отношению к ВВП снизился более чем на $20 \%$ за последние десятилетия: в начале 2000 -х гг. значение составляло 48,9\%, по итогам 2018 г. - 27,6\%. При этом динамика объёма государственного долга на душу населения обратная - за период 1990-2019 гг. произошло его повышение в 2 раза в связи с тем, что за указанный период среднегодовой прирост населения не превышал $1 \%$. Проценты на обслуживание государственного долга в начале 2000-х составляли более 6\% ВВП, что существенно выше текущей доли в $1 \%$.

За рассмотренный период доля доходов и расходов федерального бюджета в структуре ВВП изменилась несущественно, при этом к 2020 г. дисбаланс сократился. Наибольший дефицит федерального бюджета наблюдался в 1993 г. (2\% ВВП), в 2008 г. сформировалось максимальное сальдо бюджета в размере $1,2 \%$ ВВП. Незначительное повышение государственного долга в плановый период 2021-2024 гг. и наличие дефицита бюджета является следствием неблагоприятных событий 2020 г.

Структура расходов федерального бюджета Швейцарии за исследуемый период отражает рост социальной ориентированности (рис. 4). На финансирование социальной сферы, включающей страхование военнослужащих, медицинское страхование, выплаты малоимущим и другие разделы, расходуется треть бюджета (31\% в 2014 г., 34\% планируется к 2024 г. Расходы на образование и науку - по итогам ис- 
полнения 2020 г. запланирован рост на 2\% по сравнению с аналогичным показателем 2014 г. На содержание транспортной системы приходится существенная доля бюджета - около 13-14\% (обслуживание и модернизация дорожного хозяйства, общественного транспорта и авиации), что обусловлено высокой зависимостью всех сфер экономики и жизнедеятельности от качества функционирования транспортного комплекса.

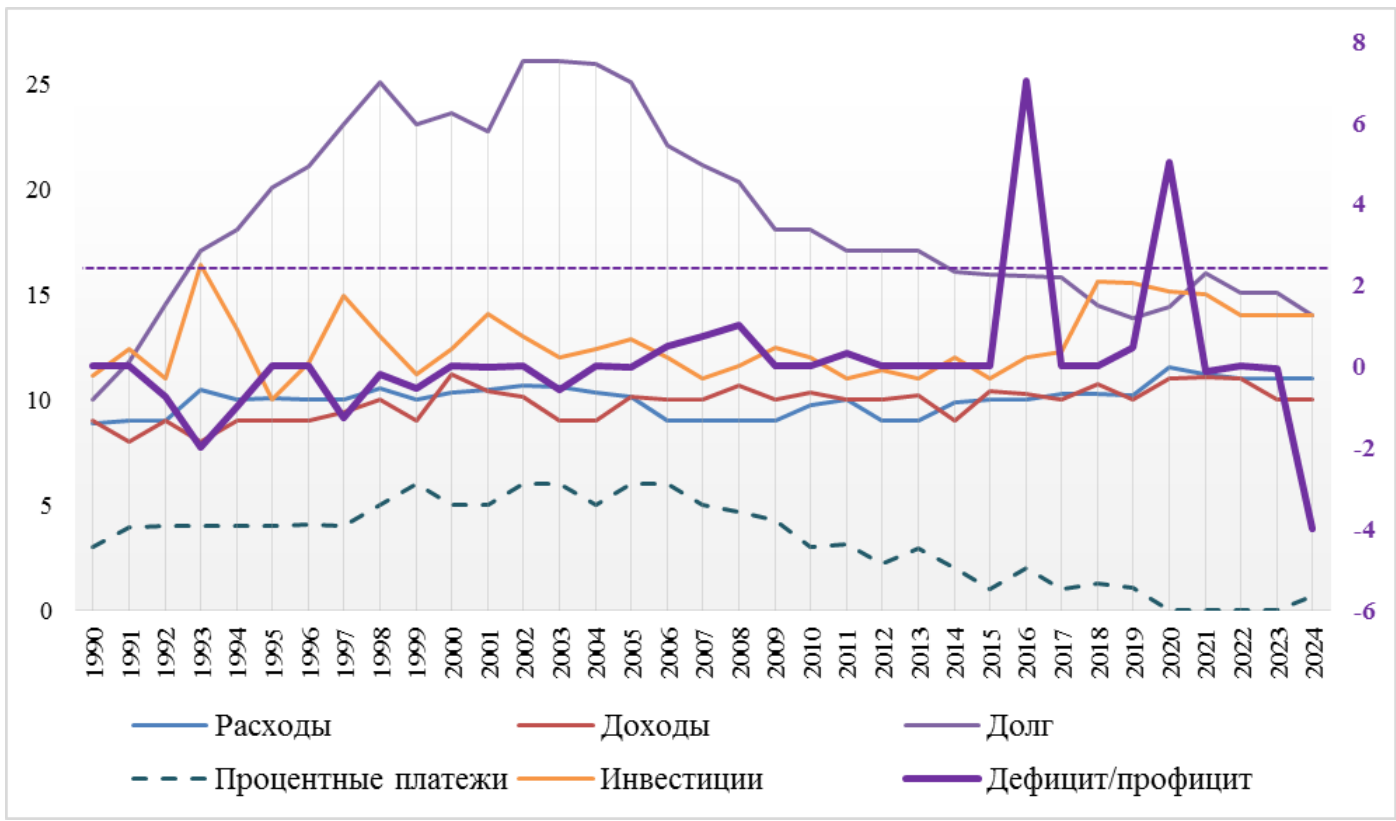

Puс. 3. Ключевые показатели федерального бюджета Швейцарии в 1990-2024 гг.

(левая шкала), дефицит/профицит федерального бюджета (правая шкала), в \% к ВВП Источник: составлено авторами на основе [6]

В статью расходов «финансы и налоги» включаются расходы на формирование капитала, управление государственным долгом, предоставление межбюджетных трансфертов иным бюджетам бюджетной системы. Стабильность структуры расходов обусловлена в частности проводимой политикой устойчивого развития посредством реализации вышеуказанных стратегий осуществляется поступательное достижение национальных целей.

Реализация расходных обязательств публично-правовых образований Швейцарии осуществляется, прежде всего, за счёт поступления налоговых доходов, доля которых составляется более 90\% в общем объёме доходов консолидированного бюджета. Однако, в связи со сложившейся в 2020 г. серьёзной эпидемиологической обстановкой, сальдо федерального бюджета Швейцарии прогнозируется отрицательным в 2021-2024 гг. (рис. 5). 
Демидова С. Е., Воронина Н. Л. Политика устойчивого развития как основа управления общественными финансами (на примере Швейцарии)

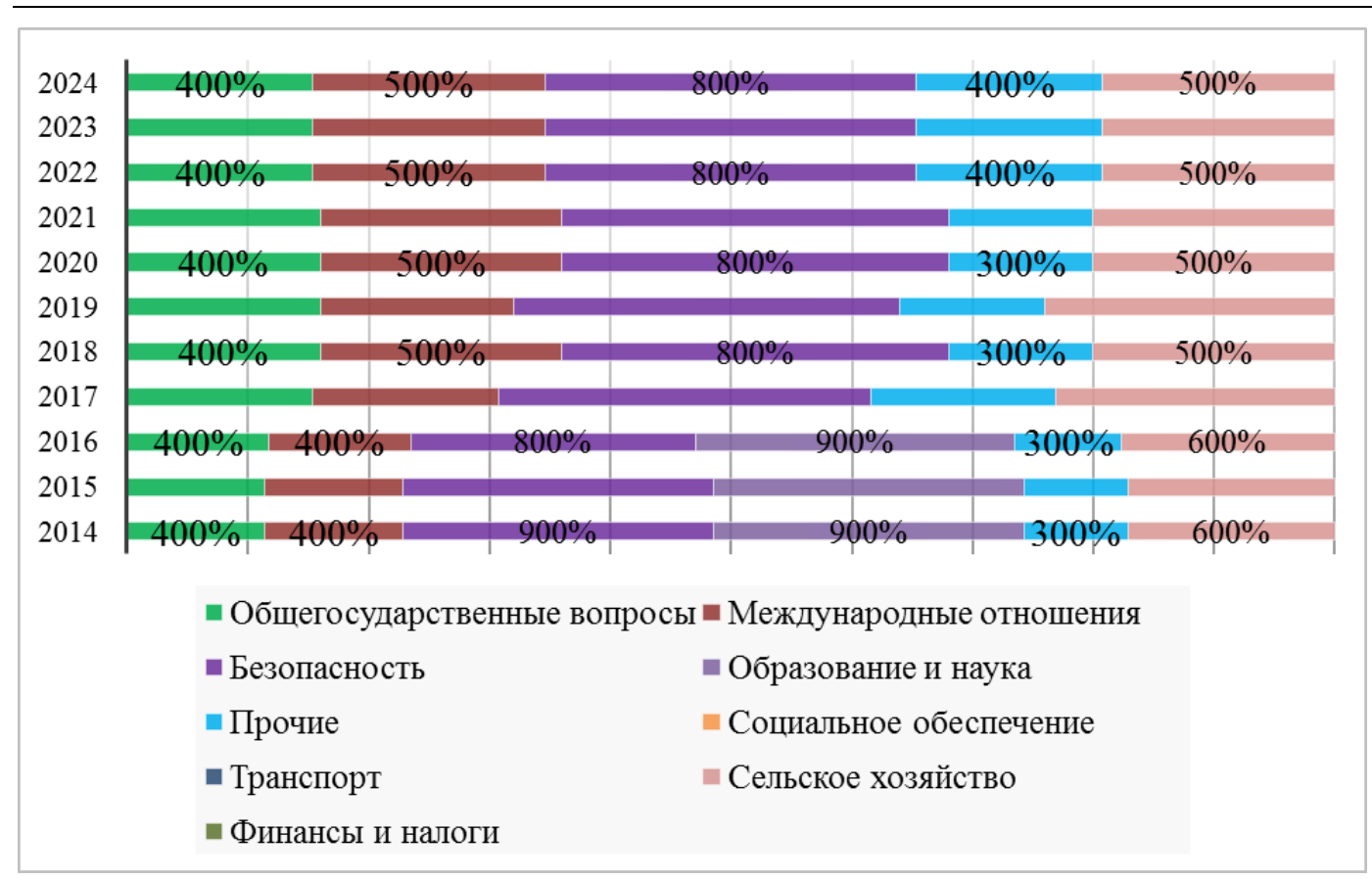

Рис. 4. Структура расходов федерального бюджета Швейцарии

$$
\text { в 2014-2024 гг., в \% }
$$

Источник: составлено авторами на основе [7]

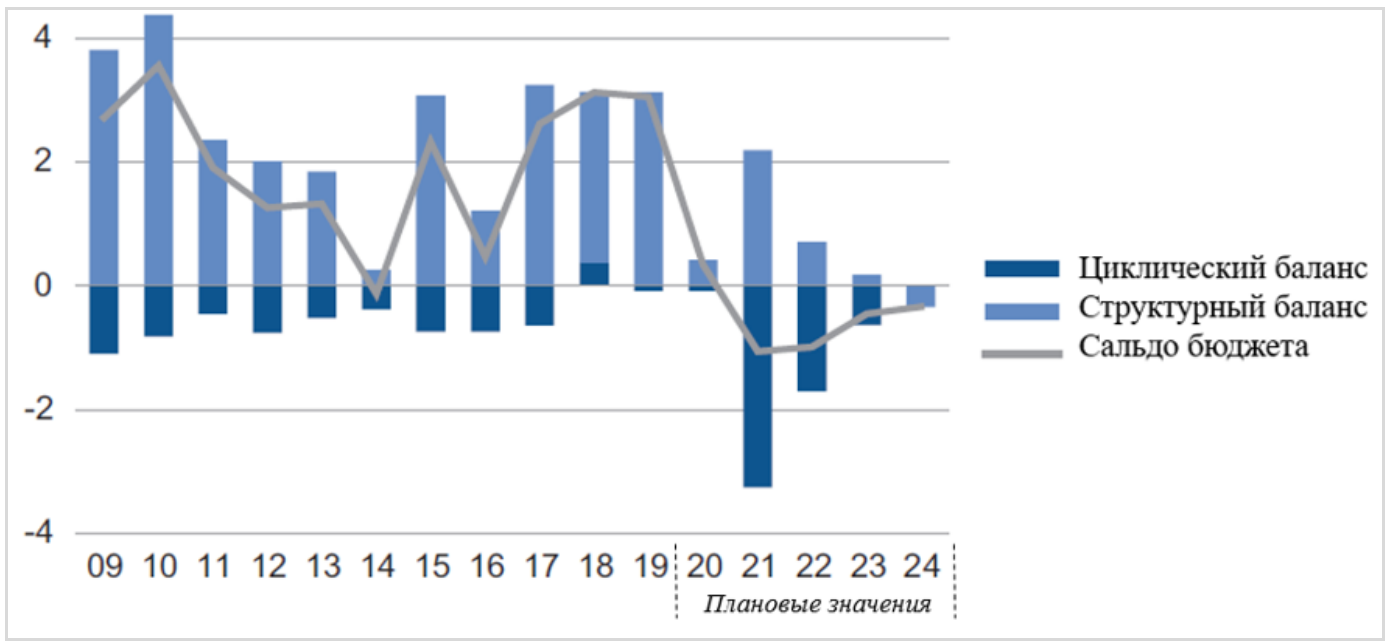

Puc. 5. Финансовый результат исполнения федерального бюджета Швейцарии Источник: составлено авторами на основе [7]

Начиная с 2014 г. Швейцария устойчиво достигала комфортного уровня профицита всех бюджетов бюджетной системы. В начале 2020 г., до реакции на пандемию, положительная тенденция должна была продолжиться. Принимаемые прави- 
тельствами меры по распространению COVID-19 и поддержки населения и отраслей экономик привели к ухудшению индикаторов общественных финансов в краткосрочной перспективе. Рекордное ослабление швейцарской экономики окажет серьёзное негативное влияние на налоговые поступления на всех уровнях бюджетной системы. Более того, увеличилась расходная часть - чрезвычайные меры были приняты на сумму около 17,8 млрд швейцарских франков, из которых 12,2 млрд взносы на страхование по безработице, уровень которой по итогам октября 2020 г. составляет 3,3\% (что на 1\% выше аналогичного периода прошлого года).

В 2021 финансовом году ожидается постепенное восстановление экономики Швейцарии. Уровень ВВП вряд ли полностью вернется к докризисному уровню, тем не менее, по причине стабилизации социально-экономической ситуации налоговые поступления будут расти. Большинство чрезвычайных мер запланировано осуществить только в 2020 г., поэтому расходы сектора государственного управления должны снизиться. Однако объём расходов фондов социального страхования всё ещё останется намного выше докризисного уровня из-за роста безработицы.

Таким образом, впервые за последние годы в Швейцарии предусмотрен циклический дефицит (разность между запланированными доходами и установленным верхним пределом расходов) в размере 3,3 млрд франков в 2021 г., который постепенно будет уменьшаться. Однако, поскольку экономика будет восстанавливаться медленными темпами, в 2024 г. циклический дефицит перейдет в структурный - объём предусмотренных расходов превысит предельные значения. Такая ситуация обусловлена применяемой контрциклической политикой «долговой тормоз», при котором во время фаз спада экономического цикла допускается определённый циклический дефицит, во время подъёма - обязательное наличие профицита. Швейцарский «долговой тормоз» считается историей успеха и упоминается как модель устойчивого сбалансированного бюджетирования, которая приводит к стабилизации государственных финансов [8]. Устойчивость общественных финансов достигается за счет сглаживания колебаний экономической активности и последствий различных шоков.

Проведение политики устойчивого развития отражается и на финансах государственных внебюджетных фондов. Так, инвестиционная стратегия Швейцарского национального фонда страхования от несчастных случаев построена на принципе долгосрочного обеспечения активами (достаточными для покрытия полного объёма страховых выплат независимо от текущей рыночной ситуации) и широкой диверсификации. Кроме того, при выборе инструмента инвестирования внимание обращается не только на соотношение риска и доходности, но и соблюдения экологических, социальных и этических принципов [9]. Относительная стабильность инвестиционной активности обусловлена типичной для большинства развитых экономик проблемой предельной загруженности мощностей и необходимостью поиска нового источника инвестиций. 
Ключевая задача на сегодняшний момент - полноценная интеграция мировых целей развития в систему национального управления общественных финансов. С другой стороны, устойчивость не может быть решена исключительно на национальном уровне, поскольку на неё влияет симбиоз внешних сложно прогнозируемых факторов.

В Российской Федерации, несмотря на наличие организационных основ функционирования и соответствующих документов стратегического планирования, в которых закреплены национальные цели развития, ещё не достигнут такой же уровень взаимоувязки показателей, как в Швейцарии, где обеспечивается качественное достижение конечных результатов, которые отражаются на конкретной целевой группе. Для отечественной практики характерно наличие большего количества документов стратегического планирования, что приводит к сложностям при формировании единой системы показателей. Несмотря на то, что косвенно в прогнозах социально-экономического развития упоминается устойчивое развитие как ключевой компонент при формировании целей и задач, в большинстве своём происходит постановка целей по конкретным сферам жизнедеятельности в отсутствии качественного и количественного анализа их взаимосвязи между собой. Сравнительная характеристика систем стратегического управления общественными финансами Швейцарии и России представлена в табл. 1.

Зачастую в России новым документом стратегического планирования происходит не корректировка планируемых результатов, а кардинальное изменение как значений, так и самих показателей. Например, Указом Президента РФ от 21.07.2020 № 474 «О национальных целях развития Российской Федерации на период до 2030 года» устанавливается целевой показатель, характеризующий достижение соответствующей цели к 2030 году - повышение ожидаемой продолжительности жизни до 78 лет. До принятия указанного акта такое же значение аналогичного показателя в соответствии с указом Президента РФ от 07.05.2018 № 204 «О национальных целях и стратегических задачах развития Российской Федерации на период до 2024 года» должно было быть достигнуто к 2024 году, а к 2030 году - 80 лет.

Счётная палата Российской Федерации по результатам проведения контрольных и экспертно-аналитических мероприятиях обращает внимание на недостатки в части определения целей, задач, результатов и характеризующих их целевые показатели: в частности, не в полной мере обеспечено соответствие и связь показателей, установленных различными стратегическими документами, по ряду государственных программ цели и задачи не корректируются или корректируются незначительно. Например, исходя из заключения Счётной палаты РФ на проект федерального закона «О федеральном бюджете на 2021 год и на плановый период 2022 и 2023 годов», 68,9\% от общего количества государственных программ не соответствуют документам стратегического развития, 64,4\% - отраслевым стратегическим документам [10]. 


\section{Сравнительная характеристика систем стратегического управления общественными финансами в аспекте устойчивого развития}

\begin{tabular}{|c|c|c|}
\hline $\begin{array}{c}\text { Элементы системы } \\
\text { стратегического УОФ }\end{array}$ & Швейцария & Россия \\
\hline $\begin{array}{l}\text { Законодательное } \\
\text { закрепление цели } \\
\text { устойчивого развития } \\
\text { в высшем законе }\end{array}$ & $\begin{array}{l}\text { Закрепление как националь- } \\
\text { ной цели в Конституции }\end{array}$ & Не закреплено \\
\hline $\begin{array}{l}\text { Ключевая националь- } \\
\text { ная цель }\end{array}$ & $\begin{array}{l}\text { Обеспечение устойчивого } \\
\text { развития }\end{array}$ & $\begin{array}{l}\text { Пять целей, установленных } \\
\text { указом Президента РФ }\end{array}$ \\
\hline $\begin{array}{l}\text { Федеральные органы } \\
\text { власти, отвечающие } \\
\text { за устойчивое развитие }\end{array}$ & $\begin{array}{l}\text { Федеральный Совет; } \\
\text { Межведомственный комитет } \\
\text { устойчивого развития; } \\
\text { Федеральное агентство } \\
\text { территориального развития } \\
\text { Иные органы по сфере } \\
\text { компетенции }\end{array}$ & $\begin{array}{l}\text { Заместители Председателя } \\
\text { Правительства, отвечающие } \\
\text { за конкретную национальную } \\
\text { цель }\end{array}$ \\
\hline $\begin{array}{l}\text { Нормативно-правовое } \\
\text { регулирование СУОФ }\end{array}$ & $\begin{array}{l}\text { Конституция Швейцарии; } \\
\text { Федеральные законы, } \\
\text { регулирующие конкретную } \\
\text { сферу деятельности }\end{array}$ & $\begin{array}{l}\text { Федеральный закон о стратеги- } \\
\text { ческом планировании }\end{array}$ \\
\hline $\begin{array}{l}\text { Вовлечение регионов, } \\
\text { муниципалитетов в } \\
\text { решение национальных } \\
\text { целей }\end{array}$ & $\begin{array}{l}\text { Принцип «мыслить глобаль- } \\
\text { но, действовать локально»; } \\
\text { В каждом регионе есть соот- } \\
\text { ветствующее министерство }\end{array}$ & $\begin{array}{l}\text { Региональный проектный офис; } \\
\text { Региональные программы и } \\
\text { проекты; } \\
\text { Закрепление персональной } \\
\text { ответственности }\end{array}$ \\
\hline $\begin{array}{l}\text { Документы стратегиче- } \\
\text { ского планирования }\end{array}$ & $\begin{array}{l}\text { Стратегия устойчивого разви- } \\
\text { тия, отраслевые стратегии }\end{array}$ & $\begin{array}{l}\text { Указы Президента РФ, } \\
\text { закрепляющие национальные } \\
\text { цели; национальные проекты; } \\
\text { прогнозы социально-экономи- } \\
\text { ческого развития, стратегии, } \\
\text { отраслевые стратегии, государ- } \\
\text { ственные программы и другие }\end{array}$ \\
\hline $\begin{array}{l}\text { Информационные си- } \\
\text { стемы }\end{array}$ & Система "MONET" & $\begin{array}{l}\text { Информационная панель Счёт- } \\
\text { ной палаты РФ }\end{array}$ \\
\hline Методология & $\begin{array}{l}\text { Трёхмерная модель, модель } \\
\text { основного капитала }\end{array}$ & $\begin{array}{l}\text { Принципы целеполагания, про- } \\
\text { гнозирования, планирования и } \\
\text { программирования }\end{array}$ \\
\hline $\begin{array}{l}\text { Учёт наднациональных } \\
\text { целей развития }\end{array}$ & $\begin{array}{l}\text { Напрямую прослеживается } \\
\text { интеграция на национальный } \\
\text { уровень }\end{array}$ & $\begin{array}{l}\text { Схожи ключевые направления } \\
\text { развития }\end{array}$ \\
\hline
\end{tabular}

Источник: составлено авторами 
Подход Швейцарии, с учётом особенностей социально-экономического развития нашей страны, функционирования государственного сектора и в целом финансовой системы может быть использован в системе управления общественными финансами в России. Внешние вызовы (пандемия) и распространение цифровых технологий могут как способствовать, так и препятствовать переходу к устойчивому развитию, сокращению неравенства, трансформации рынка труда, ответственному потреблению и производству, обеспечению экологической безопасности. Поэтому выбор целеполагания и стратегии управления будет оказывать решающее значение на качество жизни и экономический рост.

\section{Список литературы}

1. Report «Our common future» of the World Commission on Environment and Development (the Brundtland Commission), 1987. - URL: https://sustainabledevelopme nt.un.org/content/documents/5987our-common-future.pdf (дата обращения: 01.10.2020)

2. The Legatum Prosperity Index. - URL: https://www.prosperity.com/ (дата обращения: 30.10 .2020 ).

3. Federal Constitution of the Swiss Confederation. - URL: https://www.admi n.ch/opc/en/classified-compilation/19995395/index.html (дата обращения: 01.10.2020).

4. Sustainable development in Switzerland : Methodological foundations. - URL: https://www.are.admin.ch/are/en/home/sustainable-development/strategy-and-

planning/understanding-of-sustainability-in-switzerland.html (дата обращения: 01.10.2020).

5. The MONET 2030 indicator system. - URL: https://www.bfs.admin.ch/bfs/en/ho $\mathrm{me} / \mathrm{statistics} / \mathrm{sustainable-development/monet-2030.html} \mathrm{(дата} \mathrm{обращения:} \mathrm{04.10.2020).}$

6. [Государственная база данных Швейцарии] (Open Government Data). - URL: https://www.efv.admin.ch/efv/en/home/finanzberichterstattung/daten/open_gov_data1.ht $\mathrm{ml}$ (дата обращения: 05.10.2020).

7. Federal finances at a glance (entire publication), 2021 budget Overview. - URL: https://www.efv.admin.ch/dam/efv/en/dokumente/Finanzberichte/bufi/haushalt_gesamt.p df.download.pdf/haushalt_gesamt.pdf (дата обращения: 05.10.2020).

8. Zielniewicz A. The Swiss «success story» of sustainable public finance: debt restrictions and budgeting processes in the Swiss Confederation // Fiscal Rules - Limits on Governmental Deficits and Debt / ed. by F. L. Morrison. - Springer, 2016. - P. 267-297.

9. Годовые отчеты Швейцарского национального фонда страхования от несчастных случаев. - URL: https://www.suva.ch/en/the-suva/about-us/annual-report (дата обращения: 05.10.2020).

10. Заключение Счетной палаты РФ на проект федерального закона «О федеральном бюджете на 2021 год и на плановый период 2022 и 2023 годов». - URL: https://ach.gov.ru/audit/proekt-2021 (дата обращения: 20.10.2020). 


\section{References}

1. Report «Our Common Future» of the World Commission on Environment and Development (the Brundtland Commission), 1987. Available at: https://susta inabledevelopment.un.org/content/documents/5987our-common-future.pdf (accessed 01 October 2020).

2. The Legatum Prosperity Index. Available at: https://www.prosperity.com/ (accessed 30 October 2020).

3. Federal Constitution of the Swiss Confederation. Available at: https://www.ad min.ch/opc/en/classified-compilation/19995395/index.html (accessed 01 October 2020).

4. Sustainable development in Switzerland: Methodological foundations. Available at: $\quad$ https://www.are.admin.ch/are/en/home/sustainable-development/strategy-andplanning/understanding-of-sustainability-in-switzerland.html (accessed 01 October 2020).

5. The MONET 2030 indicator system. Available at: https://www.bfs.admi n.ch/bfs/en/home/statistics/sustainable-development/monet-2030.html (accessed 04 October 2020).

6. Swiss Open Government Data. Available at: https://www.efv.admin.ch/efv/en/h ome/finanzberichterstattung/daten/open_gov_data1.html (accessed 05 October 2020).

7. Federal finances at a glance (entire publication), 2021 budget Overview. Available at: https://www.efv.admin.ch/dam/efv/en/dokumente/Finanzberichte/bufi/hausha lt_gesamt.pdf.download.pdf/haushalt_gesamt.pdf (accessed 05 October 2020).

8. Zielniewicz A. The Swiss «success story» of sustainable public finance: debt restrictions and budgeting processes in the Swiss Confederation. In: Morrison F.L., ed. Fiscal Rules - Limits on Governmental Deficits and Debt. Springer, 2016, 20. pp. 267-297.

9. Annual reports of the Swiss National Accident Insurance Fund. Available at: https://www.suva.ch/en/the-suva/about-us/annual-report (accessed 05 October 2020). (In Russian).

10. Accounts Chamber of the Russian Federation Report on the draft federal law "On the federal budget for 2021 and for the planning period of 2022 and 2023». Available at: https://ach.gov.ru/audit/proekt-2021 (accessed 20 October 2020). (In Russian). 